\title{
DEPENDENCE OF $Z$-SCAN MEASUREMENTS ON THE SPATIOTEMPORAL PULSE PARAMETERS
}

\author{
N. Slavinskis, E. Murauskas, and A.S. Dement'ev \\ Institute of Physics, Center for Physical Sciences and Technology, Savanoriu 231, LT-02300 Vilnius, Lithuania \\ E-mail: aldement@ktl.mii.lt
}

Received 11 February 2011; revised 12 May 2011; accepted 21 June 2011

\begin{abstract}
We report the experimental results obtained by the closed-aperture $Z$-scan technique where Nd:YAG minilaser short pulses with different temporal pulse shapes have been used. It is shown that the nonlinear refractive index coefficient $n_{2}$ of fused silica (one of the smallest among the condensed media) can be successfully measured using the pulses with durations of about $1 \mathrm{~ns}$ and energies less than $1 \mathrm{~mJ}$. Very good compatibility between the values for the same samples of fused silica is obtained only if the temporal shapes of the used SBS-compressed, single longitudinal or multi longitudinal mode pulses are properly taken into account. It is also shown that spatial properties of the used beams should be taken account of properly. By these experiments we emphasize the significance of taking into account the temporal pulse shape profile for accurate determination of the nonlinear refractive index by the $Z$-scan technique.
\end{abstract}

Keywords: $Z$-scan, pulse shape, nonlinear refractive index, fused silica

PACS: 42.55.Xi, 42.65.Jx, 42.70.Ce

\section{Introduction}

The characterization of nonlinear optical properties of materials is of considerable interest, both from the fundamental and applied points of view. In particular, great effort has been devoted to the determination of nonlinear refraction (NLR) and absorption (NLA) mechanisms and magnitudes of different materials [14]. There are a number of methods for nonlinear refraction index $n_{2}$ measurements, but the most popular of them is the $Z$-scan method [1-11], introduced about twenty years ago (the history of $Z$-scan "discovering" see in [6]). A keen interest has lately been shown to the accuracy and reliability of the results obtained by means of this method, the main attention being paid to the influence of the finite aperture size, the thickness of samples, beam quality ratio, and similar problems [1-14]. Although hundreds of papers on $Z$-scan measurements were published and lasers with different pulse shapes and durations were used, only the original paper [5], the review papers $[1-4,7,8]$, and a few others [14, 15] obviously indicate that the results must be temporally averaged properly when the non-rectangular pulses are used. The detailed analysis of the $Z$-scan theoretical background with emphasis on the temporal pulse shape dependence was presented in [16]. It gives a useful insight into important aspects of the $Z$-scan technique that are usually overlooked. In this paper we present the experimental results of the $Z$-scan measurements obtained using pulses with different pulse shapes for fused silica for which magnitudes of the nonlinear coefficient $n_{2}$ are well established using different measurement methods [3, 17-22]. The obtained results show that measured $Z$-scan data should be properly processed for extracting the correct values of the optical Kerr nonlinear coefficient.

\section{Experimental set-up for the $Z$-scan measurements}

For the measurements of $n_{2}$ in fused silica with different pulse shapes we used a standard closed-aperture $Z$-scan experimental scheme for isotropic media (Fig. 1). Linearly polarized pulses were focused by lens $L 1$ onto a sample which was moved along the $z$ axis by the translation stage. The $\lambda / 2$ phase plate and dielectric polarizer $P$ were used to change the energy of the incident pulses. Laser pulses after the lens $L 1$ were divided by a beam splitter $B S$. Reflected part of pulses was directed to the reference photodiode $P D 1$. An aperture transmitting about $10 \%$ of the laser pulse energy (without the sample) was placed in the far field of the beam transmitted by the sample. The energy of pulses transmitted 


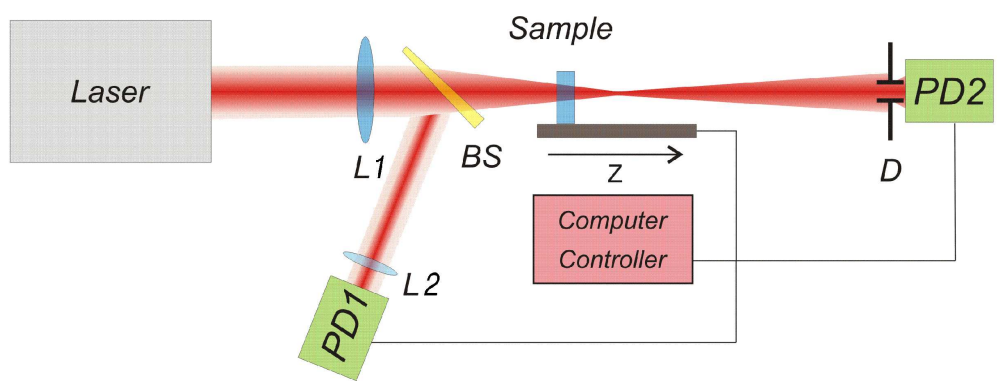

Fig. 1. Experimental set-up: Nd:YAG minilaser with or without SBS-compressor, focusing lenses $L 1$ and $L 2$, beam splitter $B S$, photodiodes $P D 1$ and $P D 2$, diaphragm $D$.

through the aperture was measured with the photodiode $P D 2$ placed directly after the aperture. Both photodiodes were synchronized with the laser. The translation stage and photodiodes through the controller were connected with a personal computer. Therefore, getting and processing of the experimental data were fully computer-assisted. At each $z$ position fifty measurements were done. For every laser pulse the data got from the photodiode $P D 2$ were divided by data got from the photodiode PD1. Then the average value and dispersion of these ratios were accepted for further processing. We used fused silica KU-1 plates with thickness of about $6 \mathrm{~mm}$ as samples for the measurements.

It is well known that the nonlinear coefficient of the optical Kerr effect in fused silica is rather low [17-22]. So, a high intensity of laser pulses is needed for $Z$-scan measurements. Therefore, we have tried first to use short pulses obtained from a SBS-compressor with tetrachloride liquid cell [23]. The SBS-compressor was pumped by a flash lamp pumped Nd:YAG master oscillator with an active electrooptical Q-switch Pockels cell with negative feedback. It generated single longitudinal mode (SLM) pulses with energy of about $4 \mathrm{~mJ}$ and of 2-4 ns adjustable duration at a repetition rate of $5 \mathrm{~Hz}$. Duration of the pulses and their shapes were measured with a system consisting of a fast photoelectric cathode connected to the analogue C7-19 oscilloscope having $5 \mathrm{GHz}$ bandwidth. A typical digitized pulse shape of compressed pulses with measured duration $\tau_{\mathrm{m}}$ is presented in Fig. 2(a). Taking into account the long enough rise time $\tau_{\mathrm{d}} \approx 100 \mathrm{ps}$ of the detection system, the real pulse width of compressed pulses can be evaluated as $\tau_{\mathrm{r}}=\left(\tau_{\mathrm{m}}^{2}-\tau_{\mathrm{d}}\right)^{1 / 2} \approx 190 \mathrm{ps}(\mathrm{FWHM})$. The energy of compressed pulses was about $2 \mathrm{~mJ}$ and could be amplified up to $16 \mathrm{~mJ}$ by the two-pass Nd:YAG amplifier. The amplified pulses were spatially filtered and after the beam cleanup procedure their beam transverse spatial profile was close to Gaussian. During the $Z$-scan experiments the energy of pulses was controlled by the attenuator consisting of $\lambda / 2$ plate and a dielectric polarizer.
The experiments carried out with the SBS pulse compression system have shown that for the measurements of the nonlinear coefficient $n_{2}$ of fused silica using the $Z$-scan technique it is enough to have pulses with energies in the interval of $0.85-1.3 \mathrm{~mJ}$ when the focusing lens $L 1$ with $f=30 \mathrm{~cm}$ is applied.

The diode pumped actively Q-switched Nd:YAG minilaser $\left(\lambda_{\mathrm{p}}=1064 \mathrm{~nm}\right.$, pulse repetition rate $\nu_{\mathrm{p}}=$ $25 \mathrm{~Hz}$ ) was used in the other set of experiments. The main advantage of this laser is its ability to generate not only SLM pulses (Fig. 2(b)) of about $\tau_{\mathrm{p}}=1.36 \mathrm{~ns}$ (FWHM) duration, but also multi longitudinal mode (MLM) pulses (Fig. 2(c)). The maximum pulse energy $W_{\mathrm{p}}$ was about $1.7 \mathrm{~mJ}$ when the SLM pulses were generated. The transverse laser mode was also close to the $\mathrm{TEM}_{00}$ mode (controlled with CCD camera) and neither the laser transverse mode nor the beam waist radius $w_{0}$ did change practically while switching between SLM or MLM pulse generation regimes. The pulse shapes were in-situ sampled using a fibre-coupled fast InGaAs photodetector (DET01CFC/M, Thorlabs, rise time $\tau_{\mathrm{d}}=100 \mathrm{ps}$ ) connected to the fast digital oscilloscope having a $12 \mathrm{GHz}$ bandwidth (TDS6124C, Tektronix). We will not describe our laser in detail here, but just indicate that switching from the SLM to MLM pulse generation regime and vice versa is performed by turning off or on the prelasing regime of the laser. When prelasing regime is turned on and adjusted correctly, $99 \%$ of the generated pulses are SLM. When it is turned off, the MLM pulses having slightly higher energy are generated. Thus, this laser allowed us to carry out $Z$-scan experiments using SLM and MLM shaped pulses in the same focusing geometry and see what the difference in the measured $Z$-scan signal was and how to correctly extract the values of the $n_{2}$ coefficient from measured data. 

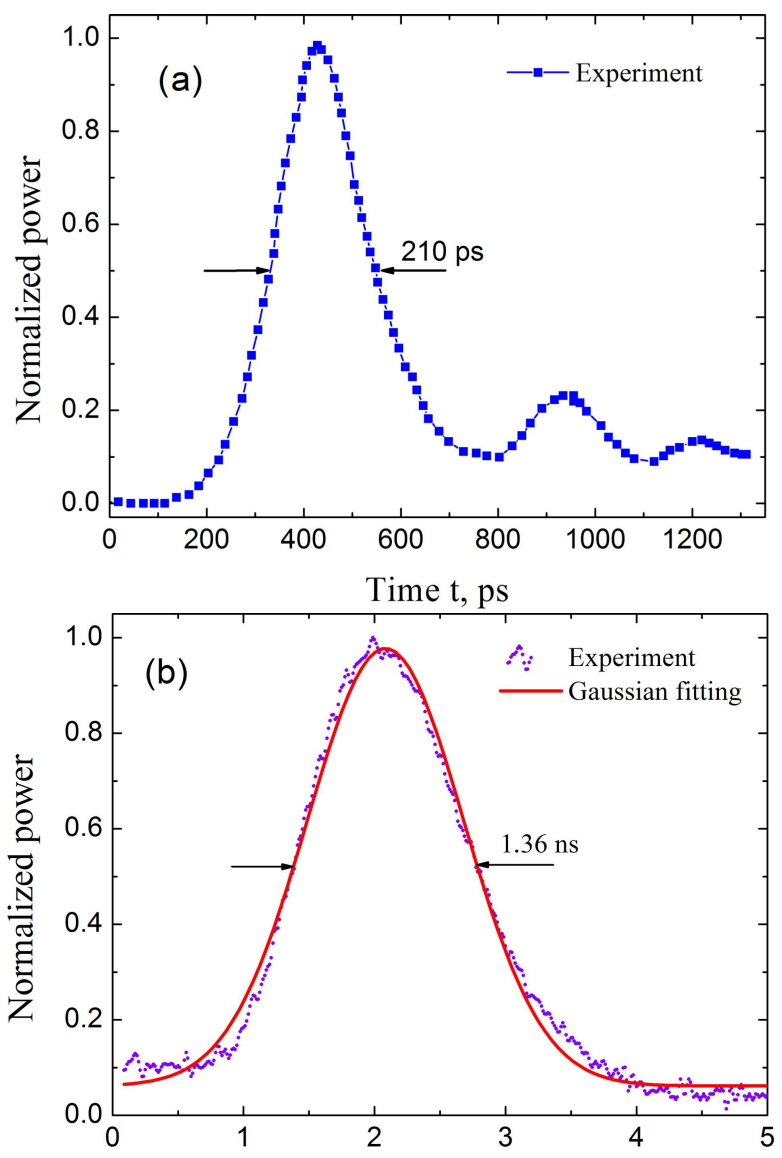

Time t, ns

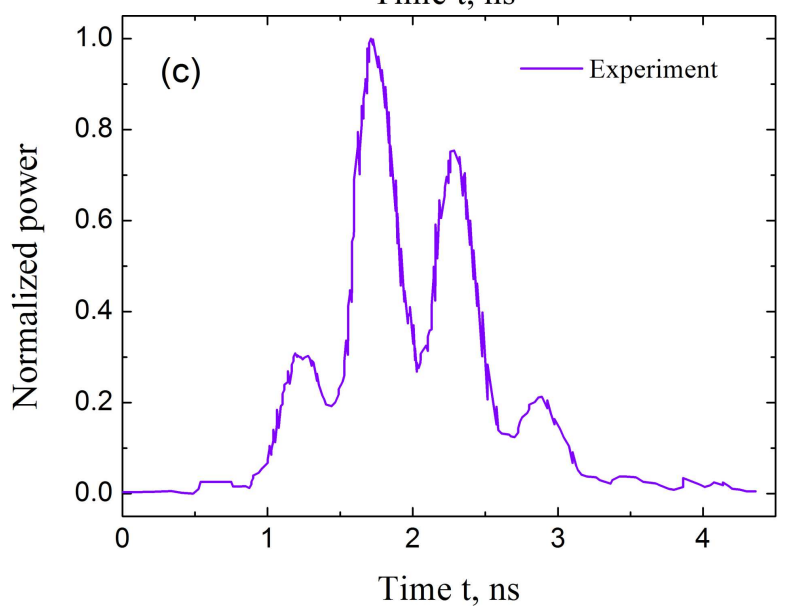

Fig. 2. Shapes of pulses used in $Z$-scan experiments: (a) pulse shape of SBS-compressor, (b) SLM pulse shape, (c) typical MLM pulse shape. The durations $\tau_{\mathrm{m}}$ measured by oscilloscope are shown at the arrows.

\section{Results and discussion}

Before discussing the obtained results it is necessary to clarify the definitions and notations used. Selfaction effects studied in nonlinear optics have a long history [1-3, 24-27]. Therefore, the same notation $n_{2}$ for the nonlinear index coefficient (NIC) is often used, applying different definitions. Throughout this paper, we will employ $n_{2}$ for linear polarization defined via

$$
\delta n(\boldsymbol{r}, t)=n_{2}\left\langle\tilde{\boldsymbol{E}}^{2}(\boldsymbol{r}, t)\right\rangle,
$$

where the change of the refractive index $\delta n(\boldsymbol{r})$ locally depends on the time-averaged square of the electric field $\left\langle\tilde{\boldsymbol{E}}^{2}(\boldsymbol{r}, t)\right\rangle$ in the medium. Taking into account that the optical intensity in the medium is defined as $I=c n_{0}\left\langle\tilde{\boldsymbol{E}}^{2}(\boldsymbol{r}, t)\right\rangle /(4 \pi)$, ignoring nonlinear corrections for $n(\boldsymbol{r})=n_{0}+\delta n(\boldsymbol{r})$, the change of the refraction index $n$ due to the optical Kerr effect can be expressed in terms of nonlinear indices $n_{2}$ (in esu units) or $\gamma_{2}$ (in SI units) through the relations

$$
n(\boldsymbol{r}, t)=n_{0}+\frac{n}{2}|\boldsymbol{E}(\boldsymbol{r}, t)|^{2}=n_{0}+\gamma_{2} I(\boldsymbol{r}, t),
$$

where $n_{0}$ is the linear part of the refractive index, $\boldsymbol{E}$ is the complex amplitude of the electric field of the beam,

$$
\tilde{\boldsymbol{E}}(\boldsymbol{r}, t)=\operatorname{Re} \boldsymbol{E}(\boldsymbol{r}, t) \exp \left[\mathrm{i}\left(k_{0} z-\omega t\right)\right],
$$

and $I$ denotes the intensity of the laser beam within the sample. $k_{0}=n_{0} \omega / c$ is the modulus of the wave vector, $\omega$ is the circular frequency. Coefficients $n_{2}$ and $\gamma_{2}$ are related through the conversion formula $n_{2}$ [esu] $=$ $\left[c n_{0} /(40 \pi)\right] \gamma_{2}\left[\mathrm{~m}^{2} \mathrm{~W}^{-1}\right]$, where $c$ is the speed of light in vacuum.

The study of the pulse shape influence is very important because in general the nonlinear refractive index is determined by several physical mechanisms, acting in a broad range of time scales [1-3, 24-27]. In non-resonant interactions and for pulse durations of about $1 \mathrm{~ns}$ the main mechanisms that contribute to the nonlinear index of refraction in solid state materials (for example, in fused silica) are electronic polarization and lattice vibrations. These mechanisms are very fast, with typical time responses of about $\sim 10^{-15}$ and $\sim 10^{-13}$ s, respectively [1-3]. Therefore, for pulse durations longer than $1-10 \mathrm{ps}$ the $\mathrm{cw}$ case is valid. Vibrational (nuclear) contribution to the nonlinear index coefficient $n_{2}$ is significant enough (10-20\% in glasses) [3]. The contribution of the electrostrictive effect is also often considered [1, 3]. According to [1], the electrostrictive NIC is $n_{2}^{\mathrm{ES}} \sim 10^{-19} \mathrm{~m}^{2} \mathrm{~V}^{-2}$, which is higher than optical Kerr NIC $\left(n_{2}^{\mathrm{K}} \sim 10^{-22}\right.$, $10^{-21} \mathrm{~m}^{2} \mathrm{~V}^{-2}$ ) for typical transparent dielectrics. But as shown by one of us previously [29], the contribution of the optical Kerr nonlinearity to the nonlinear change of the refractive index $\left(\Delta n_{\|}^{\mathrm{K}}(\omega)=11.5 \cdot 10^{-14} E_{0}^{2}\right)$ induced by the Gaussian beam with linear polarization is by an order of magnitude stronger than the electrostrictive contribution $\left(\Delta n_{\|}^{\mathrm{ES}}(\omega)=15.8 \cdot 10^{-15} E_{0}^{2}\right)$ at the 
axis of the beam for fused silica (here $E_{0}$ is the peak strength of the electric field in esu units). It should also be noted that contrary to the common claims of the known textbooks and review articles [1, 3, 28], the electrostrictive change of the refractive index strongly depends on the polarization and the intensity distribution of the beam [29, 30]. Our evaluation of electrostrictive $n_{2}^{\mathrm{ES}}$ is consistent with a very rough estimate of the magnitude of the electrostrictive nonlinear index given in the new review [3]. It follows from [3] that the electrostrictive $\gamma_{2}^{\mathrm{ES}}$ is proportional to $p_{11}^{2}\left(p_{i j}\right.$ are the elastooptical coefficients in Voigt notation) and its value is $0.4 \cdot 10^{-20} \mathrm{~m}^{2} \mathrm{~W}^{-1}$. It can be shown that in another limiting case it is proportional to $p_{12}^{2}$ [30]. These Voigt coefficients differ strongly enough for fused silica: $p_{11}=$ 0.12 and $p_{12}=0.27$ [30]. Thus, the electrostrictive contribution to NIC has typically amounted to tens of percent contribution to the Kerr effect in the stationary case [3]. Besides, it is very important that the electrostrictive response time, which is roughly equal to the time required for an acoustic deformation to travel across the diameter of the optical beam in the medium, is of about $\sim 10$ ns under our experimental conditions. Thus, the electrostrictive response is very slow, and therefore its contribution is very low as compared to the electronic and nuclear Kerr effect and cannot strongly influence our measurement results with short pulses. Time scales of thermal and other physical mechanisms of nonlinearities are even longer and do not contribute to the nonlinear transmittance in our measurements at low pulse repetition rates.

The detailed theoretical description of the procedure of taking into account the pulse shape temporal profile was done previously [16]. In the case of a small nonlinear phase change $\left|\Delta \Psi_{0}(t)\right| \ll 1$ at the beam waist position of the sample $z_{0}$ the theoretical normalized closed aperture $Z$-scan energy transmittance can be written as

$$
\begin{aligned}
& T_{\text {th }}\left(z,\left\langle\Delta \Psi_{0}(t)\right\rangle\right) \cong \\
& 1+\frac{4\left\langle\Delta \Psi_{0}(t)\right\rangle\left(z-z_{0}\right) / z_{\mathrm{R}}}{\left[9+\left(z-z_{0}\right)^{2} / z_{\mathrm{R}}^{2}\right]\left[1+\left(z-z_{0}\right)^{2} / z_{\mathrm{R}}^{2}\right]},
\end{aligned}
$$

where

$$
\left\langle\Delta \Psi_{0}(t)\right\rangle=\frac{\int_{-\infty}^{\infty} \Delta \Psi_{0}(t) P(t) \mathrm{d} t}{\int_{-\infty}^{\infty} P(t) \mathrm{d} t},
$$

is power $P(t)$ weighted time-averaged on-axial nonlinear phase change at the beam waist.
When the pulse shape $\left|f_{j}(t)\right|^{2}$, the pulse energy $W_{\mathrm{L}}$, and the intensity at the beam waist $I_{0 j}$ can be measured (here and afterwards index $j$ denotes the particular pulse shape used in the experiment), then the nonlinear refractive index can be found using formula

$$
\gamma_{2}=\eta_{j}^{(1)} \frac{\left\langle\Delta \Psi_{0 j}(t)\right\rangle_{\mathrm{fit}}}{k L_{\mathrm{eff}} I_{0 j}}
$$

where $\Delta \Psi_{0 j}(t)=k L_{\text {eff }} \gamma_{2} I_{0 j}\left|f_{j}(t)\right|^{2}, k=\omega / c=$ $2 \pi / \lambda$ is the wave number for the wavelength $\lambda$ in vacuum, $L_{\text {eff }}=\left(1-\mathrm{e}^{-\alpha L}\right) / \alpha, L$ is the thickness of the sample, $\alpha$ is the linear absorption coefficient. The coefficient $\eta_{j}^{(1)}$ describes the influence of the pulse shape and can be calculated by the formula [16]

$$
\eta_{j}^{(1)}=\frac{\int_{-\infty}^{\infty}\left|f_{j}\left(t^{\prime}\right)\right|^{2} \mathrm{~d} t^{\prime}}{\int_{-\infty}^{\infty}\left|f_{j}\left(t^{\prime}\right)\right|^{4} \mathrm{~d} t^{\prime}},
$$

where $\left|f_{j}\left(t^{\prime}\right)\right|^{2}$ is the experimentally sampled pulse shape, normalized to unity at the peak. While calculating the coefficient $\eta_{j}^{(1)}$, it is commonly assumed that the shapes of the pulse intensity and the pulse power are identical.

It is seen from the formula (6) that for the calculation of the nonlinear refractive index $\gamma_{2}$ the on axis beam intensity $I_{0 j}$ should be calculated. For Gaussian and near Gaussian beams with a known pulse shape this can be done using the formula

$$
W_{\mathrm{L}}=\frac{\pi w_{0 j}^{2}}{2} I_{0 j} \tau_{0} \int_{-\infty}^{\infty}\left|f_{j}\left(t^{\prime}\right)\right|^{2} \mathrm{~d} t^{\prime},
$$

where the beam waist radius $w_{0 j}$ is defined using the second order moment method [31-33] and $\tau_{0}$ is the time normalization unit. But simply measuring the beam waist radius $w_{0 j}$ is not enough because the transmittance described by the formula (4) depends on the Rayleigh length $z_{\mathrm{R}}$. Therefore, independent measurement of $z_{\mathrm{R}}$ should be carried out using the method of the second order moments [31-33]. As was shown in our papers [32, 33], the direct use of the alternative propagation ratios measured by varying the aperture, moving the knife or slit, which are not propagation invariants, is not appropriate for these purposes. But it can be shown that using special processing of the measured data obtained by the moving knife method the true invariant beam propagation ratio $M^{2}$ can be established not only for stigmatic beams [32, 33], but for general astigmatic beams as well. This specially developed procedure of 


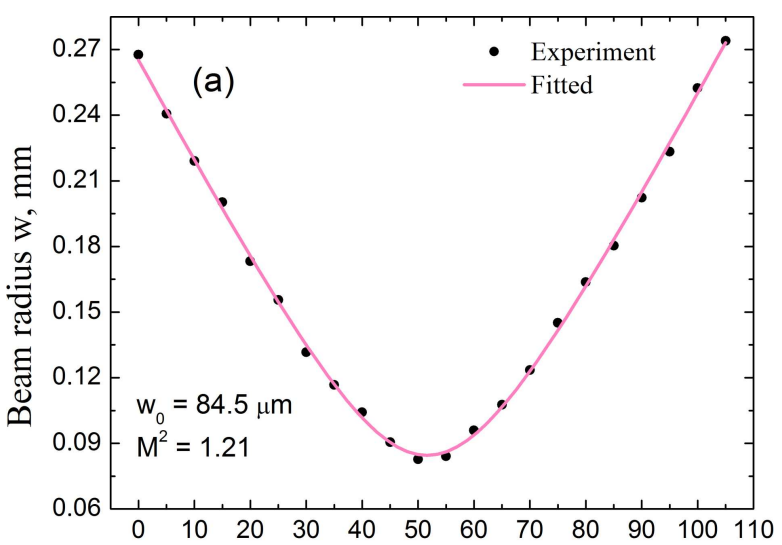

Plane of measurement $\mathrm{z}, \mathrm{mm}$

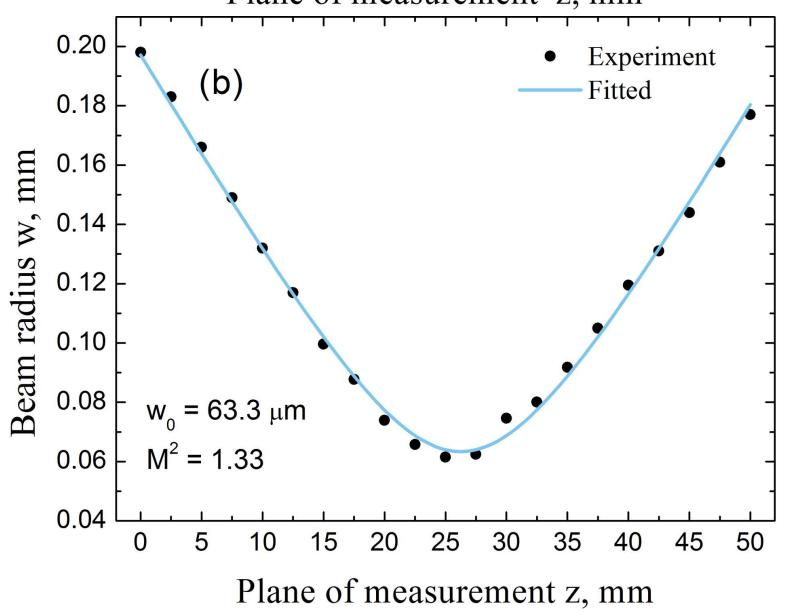

Fig. 3. Beam radii measured by the moving knife method: (a) of the Nd:YAG laser with SBS-compressor, (b) of the diode pumped actively Q-switched Nd:YAG minilaser.

measured data processing was used for measuring beam propagation ratios of SBS compressed pulses (Fig. 3(a)) and Nd:YAG minilaser pulses (Fig. 3(b)). This procedure allows getting values of the beam radii and appropriate beam propagation ratios pointed out in Fig. 3 .

As follows from the formula (6), the main parameter needed for the determination of $\gamma_{2}$ value is the power-weighted time-averaged on-axial nonlinear phase change at the beam waist $\left\langle\Delta \Psi_{0}(t)\right\rangle$, which in the $Z$-scan method is found by fitting the measured transmittance data to the formula (4) of normalized transmit- tance. The fitting procedure is not commonly described in detail in the papers devoted to the measurement of NIC of materials by the $Z$-scan technique. But as will be shown in this paper the obtained values significantly depend on the used fitting procedure. It should be noted that the formula (4) is true only for the ideal case, when the transmittance normalization is performed very exactly and the scanning is done very perfectly. But it is very difficult experimentally to avoid the walk-off effect during scanning of the sample along the beam propagation direction. Therefore, we used the following formula for fitting of experimental data:

$$
\begin{aligned}
& T_{\exp }\left(z,\left\langle\Delta \Psi_{0}(t)\right\rangle\right) \cong \\
& 1+\frac{4\left\langle\Delta \Psi_{0}(t)\right\rangle\left(z-z_{0}\right) / z_{\mathrm{R}}}{\left[9+\left(z-z_{0}\right)^{2} / z_{\mathrm{R}}^{2}\right]\left[1+\left(z-z_{0}\right)^{2} / z_{\mathrm{R}}^{2}\right]} \\
& +\Delta T-a\left(z-z_{0}\right),
\end{aligned}
$$

where the $\Delta T$ term corrects for the normalization error and the $a\left(z-z_{0}\right)$ term corrects for the walkoff effect.

First of all we present here the results of $Z$-scan measurements (Fig. 4(a)) using SBS-compressed pulses (Fig. 2(a)). For this pulse shape form calculated by formula (7) the value of the coefficient $\eta_{\mathrm{SBS}}^{(1)}$ is 1.9. The energy $W_{\mathrm{SBS}}$ of used pulses was $0.85 \mathrm{~mJ}$, $w_{0 \mathrm{SBS}}=84.5 \mu \mathrm{m}$, and the correspondent intensity $I_{0 \text { SBS }}$ at the beam waist obtained using formula (8) was $22.8 \mathrm{GW} \mathrm{cm}^{-2}$. Finally, to find $\left\langle\Delta \Psi_{0}(t)\right\rangle$ and then $\gamma_{2}$, using formula (6), we should use proper fitting of experimental data to formula (9). It should be noted that we can carry out this fitting procedure in different ways. Firstly, we can use the value of $z_{\mathrm{R}}$ found by independent measurement of $M^{2}=1.21$ (Fig. 3(a)). Another possibility is to assume that the used beam has practically a Gaussian transverse profile of intensity, and therefore we can fix $M^{2}=1.00$ and use an appropriate value of $z_{\mathrm{R}}$. And the third possibility is to alternate all parameters during the fitting procedure, including the values of $z_{\mathrm{R}}$. How the values of appropriate parame-

Table 1. Values of appropriate parameters obtained by different fitting procedures in the case when SBS-compressed pulses were used.

\begin{tabular}{cccc}
\hline & $M^{2}=1.21$ & $M^{2}=1$ & All parameters fitted \\
\hline$z_{0}$ & $59.52 \pm 1.34 \mathrm{~mm}$ & $59.32 \pm 1.78 \mathrm{~mm}$ & $60.17 \pm 0.75 \mathrm{~mm}$ \\
$z_{\mathrm{R}}$ & $17.41 \mathrm{~mm}$ (fixed) & $21.07 \mathrm{~mm}(\mathrm{fixed})$ & $11.90 \pm 1.12 \mathrm{~mm}$ \\
$a$ & $(4.01 \pm 1.89) \cdot 10^{-5}$ & $(7.47 \pm 2.43) \cdot 10^{-5}$ & $(-1.34 \pm 1.77) \cdot 10^{-5}$ \\
$\Delta T$ & $(2.6 \pm 0.77) \cdot 10^{-3}$ & $(2.7 \pm 0.92) \cdot 10^{-3}$ & $(2.1 \pm 0.62) \cdot 10^{-3}$ \\
$\left\langle\Delta \Psi_{0}(t)\right\rangle$ & $(1.11 \pm 0.08) \cdot 10^{-1}$ & $(1.06 \pm 0.09) \cdot 10^{-1}$ & $(1.33 \pm 0.11) \cdot 10^{-1}$ \\
$\gamma_{2}$ & $2.78 \cdot 10^{-16} \mathrm{~cm}^{2} \mathrm{~W}^{-1}$ & $2.65 \cdot 10^{-16} \mathrm{~cm}^{2} \mathrm{~W}^{-1}$ & $3.33 \cdot 10^{-16} \mathrm{~cm}^{2} \mathrm{~W}^{-1}$ \\
$n_{2}$ & $0.96 \cdot 10^{-13} \mathrm{esu}$ & $0.92 \cdot 10^{-13} \mathrm{esu}$ & $1.15 \cdot 10^{-13} \mathrm{esu}$ \\
\hline
\end{tabular}



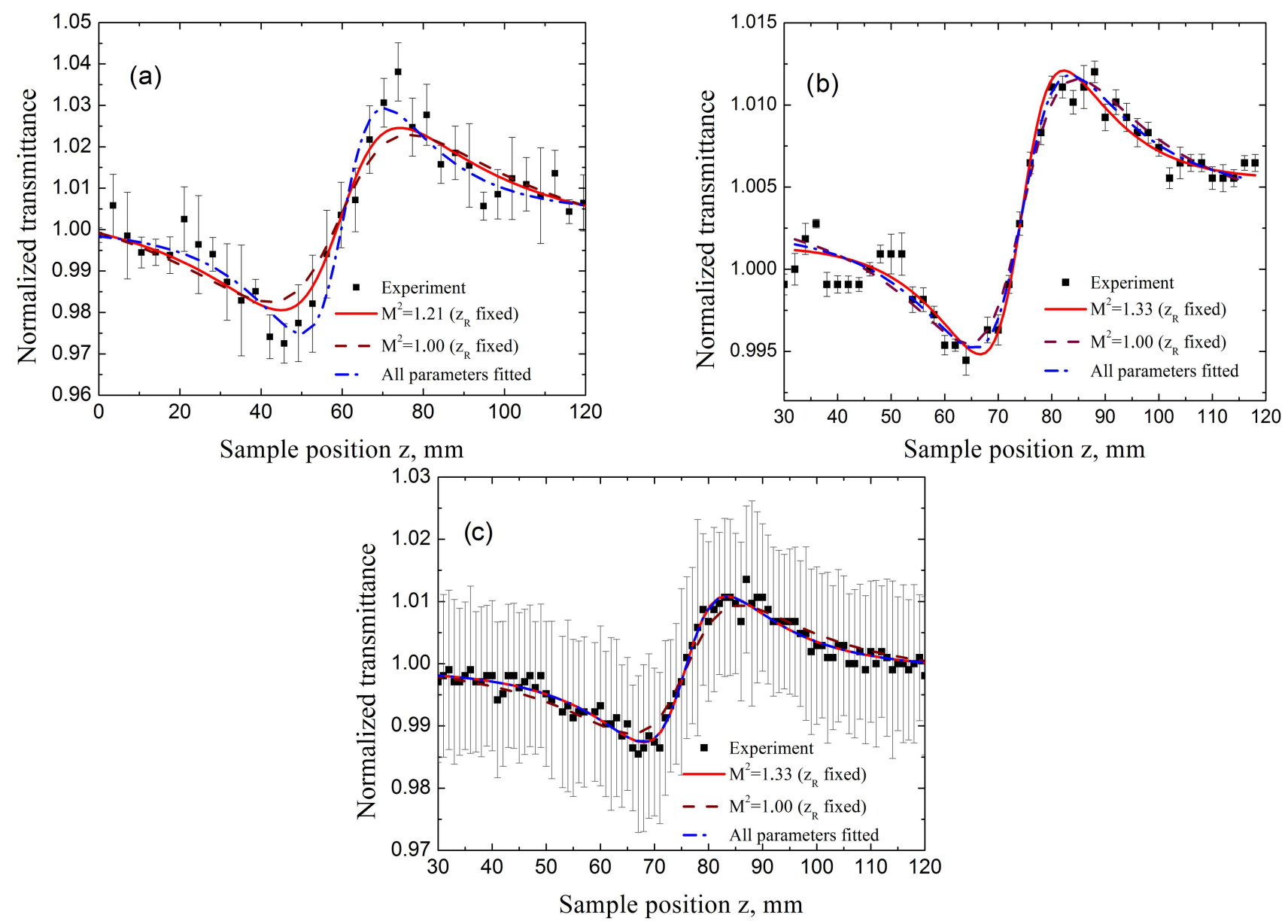

Fig. 4. $Z$-scan dependences of the normalized transmittance versus the sample position when different pulses were used: (a) SBS-compressed pulses, (b) SLM pulses, (c) MLM pulses.

ters are changing by using different fitting procedures (Fig. 4(a)) can be seen from Table 1.

The same processing procedure applied to the data obtained using SLM pulses (Fig. 2(b)) of the Nd:YAG minilaser (Fig. 4(b)) with the pulse energy $W_{\mathrm{L}}=$ $0.80 \mathrm{~mJ}$ gives the results presented in Table 2 . It is seen from these tables that the values of $\gamma_{2}$ obtained using values for $z_{\mathrm{R}}$ of independent measurements notably differ from the values of $\gamma_{2}$ calculated using other fitting methods. Although all obtained values for $\gamma_{2}$ are consistent with values for fused silica known from literature [3, 17-22], we assume that the values of $\gamma_{2}$ obtained by taking into account independent measurements of $z_{\mathrm{R}}$ are preferable due to their more logical determination. It is significant also to note that for calculation of on-axis intensity the measured pulse profile with $\tau_{\mathrm{m}}=210$ ps pulse duration (Fig. 2(a)) was used. The real pulse duration (as discussed previously) is notably shorter, $\tau_{\mathrm{r}}=190 \mathrm{ps}$, and the real on-axis intensity is higher. Therefore, we assume that the value of $\gamma_{2}$ can be evaluated more exactly using approximate formula $\gamma_{2}^{*} \approx \gamma_{2} \tau_{\mathrm{r}} / \tau_{\mathrm{m}} \approx 2.52 \cdot 10^{-16} \mathrm{~cm}^{2} \mathrm{~W}^{-1}$. Thus,

Table 2. Values of appropriate parameters obtained by different fitting procedures in the case when SLM pulses were used.

\begin{tabular}{cccc}
\hline & $M^{2}=1.33$ & $M^{2}=1$ & All parameters fitted \\
\hline$z_{0}$ & $74.43 \pm 0.32 \mathrm{~mm}$ & $74.54 \pm 0.38 \mathrm{~mm}$ & $74.50 \pm 0.34 \mathrm{~mm}$ \\
$z_{\mathrm{R}}$ & $8.89 \mathrm{~mm}$ (fixed) & $11.83 \mathrm{~mm}(\mathrm{fixed})$ & $10.35 \pm 0.76 \mathrm{~mm}$ \\
$a$ & $(-2.94 \pm 0.7) \cdot 10^{-5}$ & $(3.95 \pm 0.78) \cdot 10^{-5}$ & $(-1.28 \pm 1.12) \cdot 10^{-5}$ \\
$\Delta T$ & $(3.50 \pm 0.17) \cdot 10^{-3}$ & $(3.50 \pm 0.17) \cdot 10^{-3}$ & $(3.50 \pm 0.17) \cdot 10^{-3}$ \\
$\left\langle\Delta \Psi_{0}(t)\right\rangle_{\mathrm{fit}}$ & $(4.14 \pm 0.20) \cdot 10^{-2}$ & $(3.98 \pm 0.19) \cdot 10^{-2}$ & $(4.04 \pm 0.19) \cdot 10^{-2}$ \\
$\gamma_{2}$ & $2.55 \cdot 10^{-16} \mathrm{~cm}^{2} \mathrm{~W}^{-1}$ & $2.45 \cdot 10^{-16} \mathrm{~cm}^{2} \mathrm{~W}^{-1}$ & $2.49 \cdot 10^{-16} \mathrm{~cm}^{2} \mathrm{~W}^{-1}$ \\
$n_{2}$ & $0.88 \cdot 10^{-13} \mathrm{esu}$ & $0.85 \cdot 10^{-13} \mathrm{esu}$ & $0.86 \cdot 10^{-13} \mathrm{esu}$ \\
\hline
\end{tabular}


the agreement between two independent measurements using different lasers is very good. It should also be noted that the value of $z_{\mathrm{R}}$ obtained from the $Z$-scan data when all parameters of the transmittance formula (9) are fitted differs significantly from the directly measured one. Therefore, the method of $z_{\mathrm{R}}$ measurement by the $Z$-scan technique proposed in [34] can be used only if it is exactly known that the measured beam has exactly a Gaussian transverse structure.

We should note that it is very significant to take into account the real profile of used pulses. It can be illustrated by the case when SLM pulses are used in the $Z$-scan experiments. It can be seen from Fig. 2(b) that the temporal profiles of the generated pulses are very close to the Gaussian ones. Therefore, it seems that the use of corresponding values for $\eta_{\mathrm{G}}^{(1)}=\sqrt{2}$ and $I_{\mathrm{G} 0}=4 \sqrt{\ln 2} W_{\mathrm{L}} /\left(\sqrt{\pi^{3}} \tau_{\mathrm{G}} w_{0 \mathrm{G}}^{2}\right)=8.78 \mathrm{GW} \mathrm{cm}^{-2}$ can be good enough. But the simple calculations used in obtaining results presented in Table 2 show that $\eta_{\mathrm{SLM}}^{(1)}=1.56$ and $I_{0 \mathrm{SLM}}=7.53 \mathrm{GW} \mathrm{cm}^{-2}$. Thus, the approximation of the real SLM pulse profile by the Gaussian profile leads to the value of $\gamma_{2}=$ $1.97 \cdot 10^{-16} \mathrm{~cm}^{2} \mathrm{~W}^{-1}$, i.e. 1.29 times lower than using the procedure discussed above.

The situation was more complicated when MLM pulses were used in the experiments. In this case due to interference of all existing modes in the resonator the temporal structure of the generated pulse shape is more complex (Fig. 2(c)). It should be noted that the shape of every generated pulse is always changed slightly, but the shown pulse shape is a typical one. The experiments show that the MLM pulses have practically the same energy $W_{\mathrm{L}}$ and spatial profile, i.e. the average waist radius $\left(\overline{w_{0}^{2}} \approx w_{0 j}^{2}\right)$ and the Rayleigh length $z_{\mathrm{R}}$ are practically equal to the same for SLM pulses. It is appropriate enough to assume that in this case the nonlinear refractive index can be found using properly averaged previously used formula (6):

$$
\overline{\gamma_{2}}=\bar{\eta} \frac{\left\langle\Delta \Psi_{0 j}(t)\right\rangle_{\mathrm{fit}}}{k L_{\mathrm{eff}} \bar{I}_{0}},
$$

where $\left\langle\Delta \Psi_{0 j}(t)\right\rangle_{\text {fit }}$ is again obtained from the fitting procedure for MLM pulses, $\bar{I}_{0}=2 W_{\mathrm{L}} /\left(\pi \overline{w_{0}^{2}} \tau_{0}\right)$ is the reference intensity, and

$$
\bar{\eta}=\frac{1}{N} \sum_{j=1}^{N} \frac{\left[\int_{-\infty}^{\infty}\left|f_{j}\left(t^{\prime}\right)\right|^{2} \mathrm{~d} t^{\prime}\right]^{2}}{\int_{-\infty}^{\infty}\left|f_{j}\left(t^{\prime}\right)\right|^{4} \mathrm{~d} t^{\prime}}
$$

is a new averaged form-factor for MLM pulses. It is implicitly assumed that using every time large enough number of pulses for the averaging procedure this formfactor will be not changed. It seems that such data processing was used in [15], though it is not described in detail. Two types of the MLM pulses with durations of 7 and $20 \mathrm{~ns}$ were used in [15], and a high value of $16 \gamma_{2}$ $=(3.9 \pm 0.5) \cdot 10^{-16}$ and $\gamma_{2}=(4.9 \pm 0.6) \cdot 10^{-16} \mathrm{~cm}^{2} \mathrm{~W}^{-1}$ at $1064 \mathrm{~nm}$ were respectively obtained. This great dependence upon the pulse duration has been explained by the influence of electrostriction. As discussed above, this is not true in our opinion. Hence, the other reasons for explaining this significant deviation of obtained $\gamma_{2}$ values from the known ones for fused silica should exist. We think that the use of MLM pulses is not the best choice for the $Z$-scan experiments because the procedure of measuring and processing the data is very tedious and cannot ensure the true results.

Hence, we present here the results obtained using the MLM pulses for illustrative purposes only. We did not use the whole required procedure described above for processing the data obtained with MLM pulses. We have assumed that in our case most of generated pulses have the time profiles close to those shown in Fig. 2(c). Therefore, it has been assumed that the averaged values are practically the same as for this typical pulse. Using a previously described technique we calculated the coefficient $\overline{\eta_{\mathrm{MLM}}^{(1)}} \approx 1.9$. Then the described processing procedure was applied to the data obtained with MLM pulses of the Nd:YAG minilaser with the pulse energy $W_{\mathrm{L}}=0.68 \mathrm{~mJ}$ (Fig. 4(c)). The obtained results are presented in Table 3. First of all, it is seen from Fig. 4(c) that error bars are much larger than in Fig. 4(b). Secondly, from Fig. 4(c) we can see that the registered phase change $\left\langle\Delta \Psi_{0 j}(t)\right\rangle_{\text {fit }}$ is notably higher (1.4 times). It means that the on-axis intensity and the transmittance induced by MLM laser pulses are also higher, although lower pulse energies have been used. It is seen from Tables 1-3 that a very good compatibility between the values of $\gamma_{2}$ is obtained using different pulses. Thus, practically the same values of nonlinear coefficient $\gamma_{2}$ for the samples of fused silica are obtained when using the $Z$-scan technique only if the temporal shapes of the used pulses are properly taken into account.

\section{Conclusion}

It is shown that the nonlinear refractive index coefficient $n_{2}$ of fused silica (one of the smallest among the condensed media) can be successfully measured by 
Table 3. Values of appropriate parameters obtained by different fitting procedures in the case when MLM pulses were used.

\begin{tabular}{cccc}
\hline & $M^{2}=1.33$ & $M^{2}=1$ & All parameters fitted \\
\hline$z_{0}$ & $75.67 \pm 0.19 \mathrm{~mm}$ & $74.54 \pm 0.38 \mathrm{~mm}$ & $74.67 \pm 0.19 \mathrm{~mm}$ \\
$z_{\mathrm{R}}$ & $8.89 \mathrm{~mm}$ (fixed) & $11.83 \mathrm{~mm}($ fixed) & $8.91 \pm 0.29 \mathrm{~mm}$ \\
$a$ & $(5.53 \pm 2.64) \cdot 10^{-6}$ & $(1.92 \pm 3.43) \cdot 10^{-6}$ & $(5.61 \pm 3.00) \cdot 10^{-6}$ \\
$\Delta T$ & $(0.00 \pm 1.11) \cdot 10^{-4}$ & $(0.00 \pm 1.38) \cdot 10^{-4}$ & $(0.00 \pm 1.12) \cdot 10^{-4}$ \\
$\left\langle\Delta \Psi_{0}(t)\right\rangle_{\mathrm{fit}}$ & $(5.81 \pm 0.14) \cdot 10^{-2}$ & $(5.16 \pm 0.15) \cdot 10^{-2}$ & $(5.80 \pm 0.15) \cdot 10^{-2}$ \\
$\gamma_{2}$ & $2.59 \cdot 10^{-16} \mathrm{~cm}^{2} \mathrm{~W}^{-1}$ & $2.30 \cdot 10^{-16} \mathrm{~cm}^{2} \mathrm{~W}^{-1}$ & $2.58 \cdot 10^{-16} \mathrm{~cm}^{2} \mathrm{~W}^{-1}$ \\
$n_{2}$ & $0.90 \cdot 10^{-13} \mathrm{esu}$ & $0.80 \cdot 10^{-13} \mathrm{esu}$ & $0.89 \cdot 10^{-13} \mathrm{esu}$ \\
\hline
\end{tabular}

the $Z$-scan techniques using the pulses of simple and robust actively or passively Q-switched diode pumped $\mathrm{Nd}$ :YAG minilasers with durations of about $1 \mathrm{~ns}$ and energies less than $1 \mathrm{~mJ}$. Good compatibility between the values of $n_{2}$ or $\gamma_{2}$ for the same samples of fused silica is obtained only if the temporal shapes of the used SBScompressed, SLM or MLM pulses are properly taken into account. It is also shown that spatial properties of the used beams should be taken into account properly. The obtained results confirm our opinion that the contribution of electrostriction to the value of $n_{2}$ is small enough (less than 15\%) for stationary conditions and is practically negligible for used pulses shorter than $1 \mathrm{~ns}$.

\section{References}

[1] R.L. Sutherland, with contributions by D.G. McLean and S. Kirkpatrick, Handbook of Nonlinear Optics, Optical Engineering Vol. 82, 2nd ed. (Marcel Dekker, Inc., New York, 2003).

[2] Self-focusing: Past and Present. Fundamentals and Prospects, Topics in Applied Physics Vol. 114, eds. R.W. Boyd, S.G. Lukishova, and Y.R. Shen (Springer, 2009).

[3] D.N. Christodoulides, I.C. Khoo, G.J. Salamo, G.I. Stegeman, and E.W. Van Stryland, Nonlinear refraction and absorption: mechanisms and magnitudes, Adv. Opt. Photon. 2(1), 60-200 (2010).

[4] M. Rumi and J.W. Perry, Two-photon absorption: an overview of measurements and principles, Adv. Opt. Photon. 2(3), 451-518 (2010).

[5] M. Sheik-Bahae, A.A. Said, T.-H. Wei, D.J. Hagan, and E.W. Van Stryland, Sensitive measurement of optical nonlinearities using a single beam, IEEE J. Quantum Electron. 26(4), 760-769 (1990).

[6] "Discovering" $Z$-scan; Celebrating the $Z$-scan Technique, IEEE LEOS Newsletter 21(1), 28-29 (2007).

[7] P.B. Chapple, J. Staromlynska, J.A. Hermann, and T.J. Mckay, Single-beam $Z$-scan: measurement techniques and analysis, J. Nonlinear Opt. Phys. Mater. 6(3), 251-293 (1997).

[8] E.W. Van Stryland and M. Sheik-Bahae, $Z$-scan measurements of optical nonlinearities, in: Characteri- zation Techniques and Tabulations for Organic Nonlinear Materials, Optical Engineering Vol. 60, eds. M.G. Kuzyk and C.W. Dirk (Marcel Dekker Inc., New York, 1998) pp. 655-692.

[9] G.L. Wood and E.J. Sharp, Nonlinear Optics, in: Electro-Optics Handbook, 2nd ed., eds. R.W. Waynant and M.N. Ediger (McGraw-Hill, New York, 2000) pp. 13.1-13.28.

[10] M. Sheik-Bahae and M.P. Hasselbeck, Third-order optical nonlinearities, in: Handbook of Optics, Vol. IV, 3rd ed., ed. M. Bass (McGraw-Hill, New York, 2009) pp. 16.1-16.36.

[11] A. Dement'ev, A. Jovaiša, and R. Navakas, Modified $Z$-scan method for determination of nonlinear refraction of optical materials through the measurement of power-weighted timeaveraged beam propagation factor, Proc. SPIE 4932, 286-295 (2003).

[12] B. Gu, X-Q. Huang, S.-Q. Tan, and H.-T. Wang, A precise data processing method for extracting $\chi^{(3)}$ from Z-scan technique, Opt Commun. 277, 209-213 (2007).

[13] L. Pálfalvi, B.C. Tóth, G. Almási, J.A. Fülöp, and J. Hebling, A general Z-scan theory, Appl. Phys. B 97, 679-685 (2009).

[14] T. Shimada, N.A. Kurnit, and M. Sheik-Bahae, Measurement of nonlinear index by a relay-imaged top-hat Z-scan technique, Proc. SPIE 2714, 52-60 (1996).

[15] T. Olivier, F. Billard, and H. Akhouayri, Nanosecond $Z$-scan measurements of the nonlinear refractive index of fused silica, Opt. Express 12(7), 1377-1382 (2004).

[16] A. Dement'ev and A. Jovaisa, Pulse shape influence on the accuracy of $Z$-scan measurements, Nonlin. Analysis Model. Control 10(2), 119-136 (2005).

[17] R. Adair, L.L. Chase, and S.A. Payne, Nonlinear refractive index of optical crystals, Phys. Rev. B 39(5), $3337-3350$ (1989).

[18] A.J. Taylor, G. Rodriguez, and T.S. Clement, Determination of $n_{2}$ by direct measurement of the optical phase, Opt. Lett. 21(22), 1812-1814 (1996).

[19] D. Milam, Review and assessment of measured values of the nonlinear refractive-index coefficient of fused silica, Appl. Opt. 37(3), 546-550 (1998).

[20] I.E. Aber, M.C. Newstein, and B.A. Garetz, Femtosecond optical Kerr effect measurements in silicate glasses, J. Opt. Soc. Am. B 17(1), 120-127 (2000). 
[21] Y.-F. Chen, K. Beckwitt, F.W. Wise, B.G. Aitken, J.S. Sanghera, and I.D. Aggarwal, Measurement of fifth- and seventh-order nonlinearities of glasses, J. Opt. Soc. Am. B 23(2), 347-352 (2006).

[22] A.V. Smith and B.T. Do, Bulk and surface laser damage of silica by picosecond and nanosecond pulses at 1064 nm, Appl. Opt. 47(26), 4812-4832 (2008).

[23] A. Dement'ev, R. Buzelis, E. Kosenko, E. Murauskas, and R. Navakas, Solid-state lasers with pulse compression by transient stimulated Brillouin and Raman scattering, Proc. SPIE 4415, 92-97 (2001).

[24] S.A. Akhmanov, R.V. Khokhlov, and A.P. Sukhorukov, Self-focusing, self-defocusing and self- modulation of laser beams, in: Laser Handbook, Vol. 2, ed. F.T. Arecchi (North-Holland, 1972), pp. 1151-1228.

[25] V.N. Lugovoy and A.M. Prokhorov, Teoriya rasprostraneniya moshchnogo lazernogo izlucheniya $\mathrm{v}$ nelineynoy srede, Usp. Fiz. Nauk 111(2), 203-247 (1973) [in Russian; English translation: Sov. Phys. Usp. 16(5), 658 (1974)].

[26] O. Svelto, Self-focusing, self-trapping, and self-phase modulation of laser beams, in: Progress in Optics, Vol. XII, ed. E. Wolf (North-Holland, 1974) pp. 1-31.

[27] R.W. Hellwarth, Third-order optical susceptibilities of liquids and solids, Prog. Quantum Electron. 5, 1-68, (1977).
[28] R.W. Boyd, Nonlinear Optics, 3rd ed. (Academic Press, 2008).

[29] A.S. Dement' ev, E.K. Maldutis, and S.V. Sakalauskas, Optical anisotropy, induced in glasses by intensive laser radiation, Quantum Electronics (Kiev) 15, 62-76 (1978) [in Russian].

[30] A.S. Dement'ev, E.K. Maldutis, and S.V. Sakalauskas, Electrostrictive change of refraction index of glasses in elliptical laser beams, Opt. Spektrosk. [Opt. Spectrosc., in Russian] 50(1), 143149 (1981).

[31] A. Dementiev, D. Steponavičius, and R. Buzelis, Quality parameters of general astigmatic laser beams and their measurement, Matavimai Nr. 1(25), 7-13 (2003) [in Lithuanian].

[32] A. Dementiev, R. Navakas, R. Čiegis, and G. Šilko, Analysis of the ISO alternative measurement methods of laser beam widths and propagation factors, Matavimai Nr. 4(28), 17-22 (2003) [in Lithuanian].

[33] A.S. Dementiev, A. Jovaisa, G. Silko, and R. Ciegis, On alternative methods for measuring the radius and propagation ratio of axially symmetric laser beams, Quant. Electron. 35(11), 1045-1052 (2005).

[34] N.Y. Tabiryan, V. Jonnalagadda, M.J. Mora, and S.R. Nersisyan, Laser beam and optics characterization with "z-scan" method, Proc. SPIE 4932, 656-666 (2003).

\title{
Z SKENAVIMO MATAVIMŲ PRIKLAUSOMYBĖ NUO ERDVINIŲ IR LAIKINIŲ IMPULSŲ PARAMETRŲ
}

\author{
N. Slavinskis, E. Murauskas, A.S. Dementjev \\ Fiziniu ir technologijos mokslu centro Fizikos institutas, Vilnius, Lietuva
}

\begin{abstract}
Santrauka
Pateikiami $Z$ skenavimo su uždara apertūra eksperimentiniai rezultatai, kuriems gauti naudoti Nd:YAG minilazerio trumpi impulsai su skirtingomis laikinemis impulsų formomis. Parodyta, kad netiesinio lūžio rodiklis $n_{2}$ kvarciniam stiklui (vienas iš mažiausių kondensuotoms terpèms) gali buti sẻkmingai išmatuotas naudojant impulsus, kurių trukmė apie $1 \mathrm{~ns}$ ir energija mažesnė negu $1 \mathrm{~mJ}$. Labai geras išmatuotu verčių suderinamumas gaunamas tik tada, kai
\end{abstract}

apdorojant rezultatus yra deramai atsižvelgiama į priverstinės Brijueno sklaidos kompresijos metu gaunamas ir vienos bei kelių išilginių modų generuojamų impulsų formas. Taip pat parodyta, kad apdorojant rezultatus reikia teisingai įskaityti naudojamų pluoštų erdvinius parametrus. Šiais eksperimentais akcentuojama impulsų formos įskaitymo svarba vertinant medžiagų netiesinị lūžio rodiklị iš $Z$ skenavimo eksperimentinių duomenų. 